\title{
Fighting contraband tobacco: an opportunity for First Nations leadership and partnership
}

\author{
Matthew B. Stanbrook MD PhD
}

See related research article by Mecredy and colleagues on page E287 and at www.cmaj.ca/lookup/doi/10.1503/cmaj.111861

$\mathrm{T}$ obacco is a rare example of an addictive substance that First Nations people introduced to Europeans, not the other way around as with alcohol and other addictive substances. Unlike Europeans in these latter examples, the Aboriginals who first shared their tobacco traditions with European explorers did so without knowledge or intent regarding the devastating health and social consequences that would ensue.

Centuries later, the spread of tobacco from First Nations communities has new relevance. Contraband tobacco, which includes legally produced tobacco sold without payment of all applicable taxes, illegally produced tobacco and counterfeit tobacco products, ${ }^{1}$ poses a major obstacle to tobacco control globally. Its availability also poses a substantial barrier to smoking cessation, as shown by Mecredy and colleagues in a related article in $C M A J{ }^{2}$ Cheap prices make contraband tobacco more accessible to youth, perpetuating the smoking epidemic. These factors are a major reason why the decline in smoking prevalence has plateaued in Canada in recent years.

The vast majority of contraband tobacco currently supplied to Canadians originates from a handful of First Nations reserves that straddle border areas shared by Ontario, Quebec and New York State. These reserves have also long been sites of legal tobacco production and sales. ${ }^{3}$ But the dominance of First Nations as the source of contraband tobacco is a recent phenomenon emerging over the last decade. Blame for contraband tobacco must not be placed unduly on First Nations people generally, because the contraband trade is perpetuated by many non-Aboriginals and has now fallen largely under the control of organized crime.

Nevertheless, contraband tobacco is now inextricably linked with Aboriginal issues, posing substantial political, cultural and economic barriers to combatting it. First Nations leaders are concerned about the impact of organized crime and illegal tobacco operations in their communities. However, tobacco production and sales, legal and illegal, are the major economic engine in these same communities. ${ }^{3}$ Policies that focus on economic levers against tobacco may therefore be seen by First Nations as threatening and foster cynicism regarding government's motives. Also, perceived lack of consultation and direct involvement of First Nations in developing policy initiatives has previously resulted in lack of community support. ${ }^{3}$

Encouragingly, the federal government has taken action. In May 2008, it launched the RCMP (Royal Canadian Mounted Police) Contraband Tobacco Enforcement Strategy ${ }^{1}$ and formed the federal Task Force on Illicit Tobacco Products. To their credit, these initiatives were designed with the explicit involvement and participation of First Nations leaders and communities. For example, federal funding has been provided to the Akwesasne Mohawk Police Service to enable it to work jointly with the RCMP, the Ontario Provincial Police and the Canadian Border Services Agency to crack down on illegal tobacco activity. This collaborative effort has already led to major seizures of contraband tobacco products. ${ }^{1}$

In March 2013, the federal government announced the creation of a new anti-contraband force of 50 RCMP officers to target illegal tobacco sales. ${ }^{4}$ It also introduced legislation that creates a new Criminal Code offence for trafficking in contraband tobacco, thereby treating it in a manner similar to the trafficking of other illegal drugs. This new legislation signals a commitment by the government to increase efforts to combat illegal tobacco activity, highlights the seriousness of this criminal activity to the public and will hopefully be a deterrent to involvement in the contraband tobacco market. But the continued success of the fight against contraband tobacco will need to rely increasingly on policies that address the economic incentives keeping First Nations communities directly or indirectly tied to the contraband tobacco market. This creates an opportunity and a need for First Nations people to take the lead and guide us in freeing their communities from contraband tobacco activity while respecting cultural sensitivity and autonomy.

The Protocol to Eliminate Illicit Trade in Tobacco Products, ${ }^{5}$ adopted in November 2012 by the World Health Organization Framework Convention on Tobacco Control and awaiting Canada's signature, explicitly calls for promoting the participation of indigenous peoples and communities in creating and delivering strategies for tobacco control. Canada helped create this treaty, and our government's recent actions reflect its spirit. We call on all of Canada's governments, Aboriginal and non-Aboriginal, to continue to seek new and deeper partnerships to fight contraband tobacco activity and decrease tobacco use among all Canadians.

For references, see Appendix 1, available at www.cmaj.ca/lookup/suppl/doi: 10.1503/cmaj.130377/-/DC1.

Competing interests: See www.cmaj.ca/site/misc/cmaj_staff.xhtml

Affiliation: Matthew Stanbrook is Deputy Editor, Practice, CMAJ.

Correspondence to: $C M A J$ editor, pubs@cmaj.ca

CMAJ 2013. DOI:10.1503/cmaj.130377 